\title{
Playing in the Giant's Field: Strategies for Effectively Competing in the Global Marketplace
}

\author{
Carolan McLarney
}

This article investigates how a smaller, less resource-rich competitor can successfully out-maneuver a stronger opponent. The framework offers six arenas for resource leveraging: concentrating, accumulating, complementing, conserving, recovering, and maneuvering. The article is designed to provide small and mid-size enterprises (SMEs) strategic insights, given these companies' often limited resources and larger competitors. Using the example of a small firm, the article demonstrates that SMEs can successfully compete globally

$\mathbf{T}$ he traditional view of strategic planning, that of resource allocation, has often been criticized as being insufficient to meet strategic management requirements. Hamel and Prahalad offered the idea of strategy as stretch and leverage-as a way to expand the conventional perspective of fit and allocation. ${ }^{1}$ Refinements to the strategic planning process led to McLarney and Chung's study of the Battle of Midway, in which military leaders used strategic maneuvering to offset significant resource deficiencies. ${ }^{2}$ These authors noted that even the idea of leveraging one's resources is not necessarily adequate to offset quantitative and qualitative resource deficiencies that companies often face in the competitive marketplace. How could a smaller enterprise hope to compete with a multinational giant against overwhelming odds in managerial talents, capital resources, technological know-how, and so on?

This problem is compounded in the global marketplace, where resource imbalance is common. Indeed, even multinational giants could find themselves in an inferior position when trying to enter a local market dominated by layers of well-established relationships and networks. The literature on global strategies, however, tends to pay more attention to grander schemes of strategy and neglect the problems when resource imbalance is a hurdle. McLarney and Chung proposed an expanded view of resource leveraging, specifically to address the question of absolute resource imbalance. ${ }^{3}$ They presented the idea of maneuvering of resources as a "sixth arena" to complement Hamel and Prahalad's framework. This expanded view of strategic planning is used in this article to study the global marketing efforts of a privately owned company engaging in livestock exports. The organization has been disguised as requested by the management team. It is referred to as ABC Exports, and its CEO as Mr. Smith.
The biblical story of David and Goliath conjures up the image a small boy and his trusty sling. The underlying theme of this story and numerous others is the victory of the underling despite overwhelming odds. These stories are repeated throughout the business world. One of the questions that these tales beg is: How did the little "guy" do it? They also raise the question of: Why did the giant fall? This article explores those questions. It demonstrates that small firms can outmaneuver large ones. SMEs offer flexibility and agility, giving them a unique competitive advantage over their more massive counterparts. Secondly, the emergent themes from this analysis will provide managers of SMEs with useful new ways to contemplate strategies and to recognize that, indeed, more can be done with less. Finally, future research directions are suggested to further the knowledge about effective strategizing under adverse conditions. And with that, the strategic planning community may be better able to arrive at generalizations to guide the process.

\section{Conceptualization}

The effective and efficient allocation of resources underpins the very essence of strategic management. ${ }^{4} \mathrm{Hamel}$ and Prahalad argue that while an organization must ultimately find a fit between its resources and the opportunities it seeks, it is in the finding of that fit that strategy is created. Specifically, they contend that -"..the concept of stretch supplements the idea of fit, leveraging resources is as important as allocating them...." ${ }^{15}$ They propose several ways, "or arenas," in which organizations can achieve resource leverage with the aim of increasing resource productivity. Exhibit 1 summarizes their five arenas and the weapons of choice to be used in those arenas (the sixth arena was developed by McLarney and Chung).

The first arena of resource leverage, the concentration of resources, involves centering resources on the organization's key strategic goals. Hamel and Prahalad argue that in this arena, managers need to provide a strategic focal point. It is around this focal point that employees, functional areas, and business units can converge over time. The other tool used here is focus, which complements convergence. Convergence keeps the resources on track over time, while focus prevents their dilution as they move along the path.

The next arena is accumulation of resources in an efficient and effective manner. In this arena, the organization is centered on learning, learning not only from their own 


\begin{tabular}{|cc|}
\hline \multicolumn{1}{|c|}{ Exhibit 1 } \\
Methods of Leveraging \\
\hline $\begin{array}{c}\text { Arena of } \\
\text { Resource Leverage }\end{array}$ & $\begin{array}{l}\text { Weapons } \\
\text { of Choice }\end{array}$ \\
Concentrating & - Convergence \\
& - Focusing \\
Accumulating & - Extraction \\
Complementing & - Borrowing \\
& - Blending \\
Conserving & - Balancing \\
& - Recycling \\
Recovering & - Shielding \\
& - Expediting \\
Maneuvering & - Preempting \\
Adapted from Hamel and Prahalad, 1993.
\end{tabular}

experiences, but from those of others as well. The key is the ability not only to learn, but to learn and internalize more effectively and efficiently than your competitors. This means an environment where employees are encouraged and feel comfortable challenging the corporate status quo. In addition to extracting resources from organizational experience, firms can "borrow" skills and competencies from other companies. This borrowing also requires the internalization of those resources into the corporate knowledge base.

Complementing one type of resource with another is the third arena offered by Hamel and Prahalad. Organizations can multiply the value of resources by blending different types of resources. The blending of technological innovation with functional integration and new product development is a perfect way for firms to leverage their resources. They must, however, also balance their skills and competencies. Hamel and Prahalad warn that organizations must have strong product-development capabilities, as well as world-class production capacity (or service delivery), in addition to effective distribution/marketing/service infrastructure. Without this three-pronged attack, the firm will be lacking a vital area and will not be able to compete effectively.

Conserving resources wherever possible is the next arena of leverage. This involves recycling resources and shielding them from the competition. Hamel and Prahalad suggest that the more a certain skill or competency is utilized, the greater the resource leveraging. This means that managers must find opportunities for recycling knowledge and resources. In addition, managers must also work to protect these valuable resources from the competition that may be attempting to "borrow" them. For Hamel and Prahalad, shielding comes in the form of avoiding the competition head-on.

The fifth arena is the timely recovery of resources from the marketplace. Success in this arena is calculated as having the shortest time spent between the expenditure of resources and the recovery of those resources through revenues. The faster a firm can move to the recovery process, the better its resource leveraging.

Maneuvering resources, the sixth arena found in Exhibit 1, has been developed from an analysis of the Battle of Midway. ${ }^{6}$ This arena addresses a gap in Hamel and Prahalad's framework, namely the augmentation of already held resources to increase their leverage. The five arenas offered by Hamel and Prahalad speak to either resource allocation or resource accumulation (i.e., either where to put them or what to acquire). Maneuvering offers the opportunity to build on and increase the value of those resources already in place. Here flexibility and coordination join forces to allow organizations to garner greater resource productivity. This sixth method of resource leveraging complements and supplements the five other techniques offered by Hamel and Prahalad. In the following section, the idea behind this sixth arena (the maneuvering of resources) is briefly presented?

\section{Maneuvering of Resources}

From an analysis of the Battle of Midway, McLarney and Chung proposed a sixth arena of resource leveraging to complement Hamel and Prahalad's model. This technique is not restricted to military use and is seen in many organizations as well. The maneuvering of resources to increase productivity is directly related to allocation, but it is more than simply putting resources in their place.

Competing in the maneuvering arena requires both flexibility and coordination. The battle plans drawn up by the two sides for the Battle of Midway were at opposite ends of the flexibility spectrum. The Japanese plans, constructed solely by "senior management" (Admiral Yamamoto and his staff), were rigid in the extreme. They did not have any contingencies for the possibility of the American fleets not being at Pearl Harbor. Also, they were underpinned by the mistaken assumption that the element of surprise was theirs. The U.S. battle plans were as flexible as Japan's were rigid. Their plans were an exercise in participative decision making, with all fleet commanders having input. Also, the American commanders in the the- 
ater had much more flexibility to act, and at the same time they had the element of surprise this time. This tool of flexibility allowed the American fleet to use its scarce resources to outmanuever the Japanese.

At the same time, maneuvering also requires coordination. At the Battle of Midway, the element of coordination of the Pacific fleet was crucial to the American's victory. All ships were focused on the target, Midway. They sailed towards the enemy in balance and were united, in contrast to the Japanese who had their forces dispersed and their main battleship, Yamato, removed from the area. And, overall, their timing was far superior to the Japanese. Time and again, the Japanese were caught by surprise. Whether it was being caught with their planes being rearmed, or the miscalculation by the Japanese high altitude patrol, the Americans were "in the right place at the right time."

For effective resource leveraging to take place, resources must be in balance with one another, moving in concert with each part, and their movements must be perfectly timed. This coordination becomes increasingly important in allocating resources to maximize their flexibility. It is quite easy to lose track of where each resource is functioning. Therefore, it is vital that managers intimately know the capabilities of each resource so that they can determine the range of flexibility for that resource. Then they must know when and where they are going to allocate that resource. Each resource's allocation must be coordinated with every other resource in order to attain maximum flexibility. With maximum flexibility and effective coordination, firms can compete in the maneuvering arena and win.

\section{Maneuvering in Action: $A B C$ Exports}

$A B C$ Exports is a small firm located in the midwestern United States. Since its inception on January 17, 1977, $A B C$ has been one of the leaders in livestock exports, particularly swine, beef cattle, dairy cattle, sheep, and goats. In July 1992, ABC Exports established a sister company in the United Kingdom, $A B C$-Europe. Through this venture, $A B C$ has been able to better serve its customers as a global genetic source. ABC-Europe specializes in swine exports, but it is also the leading exporter of all types of animals from Europe.

$A B C$ 's primary goal is to supply the highest quality animals at the most competitive price. Furthermore, it aims to provide superior service, both before and after shipment, to guarantee a satisfied customer. ABC supplies genetics for all species through live animals, embryos, or semen. It continually exceeds its customers' expectations through a rigid selection process, health testing, final inspections, and follow-up service. This ensures a satisfied customer and $A B C$ 's growth through word-of-mouth sales and repeat customers. $A B C$ is the most preferred livestock exporting business in North America.
Mr. Smith, the head of ABC Exports, began his career as assistant superintendent of markets for the Illinois Department of Agriculture in charge of export promotion. Later he was general manager of lllinois Produce International. $A B C$ Exports is set up with cross-functional teams. All teams have members with either technical, regional, or administrative expertise. There are four technical experts, each specializing in a particular animal species. The three regional experts each specialize in a specific region of the world (Europe, Latin America, and Asia). The four administrative experts range in expertise in finance and accounting to marketing and administration.

\section{Strategic Analysis}

This section analyzes each arena with specific reference to $A B C$ Exports and how the firm was able to use the tools of each arena to compete more effectively in the global marketplace. This section draws on the previous discussion and specifically the new hybrid framework outlined in Exhibit 1. Exhibit 2 summarizes how the resource leverage framework relates to the strategic deployment of the resources of $A B C$ over the past 20 years.

Hamel and Prahalad's concept of leverage (and stretch) was positioned as an alternative to the traditional corporate strategy of fit. This idea of leveraging resources is argued as being as important as their allocation. ${ }^{8}$ Specifically, Hamel and Prahalad contend that "leveraging what a company already has rather than simply allocating it is a more creative response to scarcity."

\section{Concentration of Resources}

The first process by which an organization can leverage its resources is by concentrating them on key strategic goals. For resource leveraging to be successful, the resources of the organization must converge on a strategic focal point. This convergence, according to Hamel and Prahalad, "requires an intent that is sufficiently precise to guide decisions...converging resources around an amorphous goal is difficult if not impossible...."10 The concept of convergence allows organizations to keep their resources "on the right track." It, in essence, averts the possibility of the deviation of resources from the strategic goals. The concept of focus, on the other hand, helps organizations to make sure all their resources are "on the right track." Focus ensures that the organization's resources are not attenuated over time.

$A B C$ Exports. With regard to ABC Exports, this has meant a gathering of all its resources to achieve one goal: being the number one exporter of cattle and swine from the United States. This convergence of resources has allowed it to achieve this goal. In 1982, ABC Exports became the largest cattle export supplier from the United States to the Orient; and 1985, it became the number one exporter of breeding swine from the United States. This trend contin- 


\begin{tabular}{|c|c|}
\hline \multicolumn{2}{|c|}{$\begin{array}{c}\text { Exhibit } 2 \\
\text { ABC Exports' Methods of } \\
\text { Leveraging Resources }\end{array}$} \\
\hline $\begin{array}{c}\text { Arena of } \\
\text { Resource Leverage }\end{array}$ & $\begin{array}{l}\text { Weapons } \\
\text { of Choice }\end{array}$ \\
\hline Concentrating & $\begin{array}{l}\text { - All staff } \\
\text { - Cattle and swine focus }\end{array}$ \\
\hline Accumulating & $\begin{array}{l}\text { - Information and technology } \\
\text { - "Beg, borrow and steal" }\end{array}$ \\
\hline Complementing & $\begin{array}{l}\text { - Participative decision making } \\
\text { - Empowerment }\end{array}$ \\
\hline Conserving & $\begin{array}{l}\text { • "Stick with knitting" } \\
\text { • Selective focus }\end{array}$ \\
\hline Recovering & $\begin{array}{l}\text { - Rely on strength } \\
\text { - ABC-Europe }\end{array}$ \\
\hline Maneuvering & $\begin{array}{l}\text { - Innovation } \\
\text { - Technology/Databases }\end{array}$ \\
\hline Adapted from Hame & Ind Prahalad, 1993. \\
\hline
\end{tabular}

ued when, in 1990, the company was acknowledged as the largest exporter of pure-bred swine from North America. In 1995 , the firm became the top exporter of dairy cattle from the United States. Over the past 20 years, ABC Exports has consistently applied this concept of convergence to leverage its resources. Having only one goal-to be number one-has allowed $A B C$ to have a point of convergence and to win.

For ABC Exports, focus is on the export of cattle and swine specifically. This focus ensures that its resources are not scattered. This is especially evident when examining the staffing at $A B C$. Its technical experts are in the fields of dairy science, beef cattle, and swine, respectively. This concentration of expertise prevents the dilution of ABC's scarce resources into all animal species.

\section{Accumulation of Resources}

The second method of leveraging resources is through the efficient accumulation of them. Organizations are seen as a reservoir of resources, experiences, and contacts. ${ }^{1 "}$ Truly successful organizations are able to extract knowledge and productivity from this reservoir. For Hamel and Prahalad, this extraction takes place when "employees" extract value from every contact they have with clients, competitors, and other stakeholders: "...the ability to maximize the insights gained from every experience is a critical component of resource leverage."12

The accumulation of resources is also achieved through borrowing. This means borrowing from other organizations and people, be they clients, competitors, or any other stakeholders. Hamel and Prahalad add, however, that "...borrowing involves not only gaining access to the skills...but also internalizing those skills...."13 They also argue that borrowing works best then the "borrower" is hungry and aggressive rather than complacent. Complacency sometimes leads to the borrower's giving up skills rather than acquiring them. They term this phenomenon "negative leverage" and warn against falling victim to it.

$A B C$ Exports. For ABC Exports, extraction has meant moving from a very simple export business in the late 1970 s to a very sophisticated operation. In the firm's early days, the main focus was on the export of animals, which roughly meant getting the cattle or swine from the United States to the client. The selection, health testing, and final inspections of the animals drove the business. In the 1970 s, the transportation of animals was quite crude at times, with many animals expiring during their journey: In fact, many of the exporters at that time built into their bids at a 5 percent to 10 percent death rate during transport. For $\mathrm{ABC}$, this was unacceptable, so it began to investigate the major causes of the high fatality rates. What it discovered was appalling and fairly simple to fix: The mortality rates were primarily attributed to dehydration and overcrowding in the pens. Beginning in the late 1970s, ABC worked to develop "in-plane" watering systems and expanded metal penning systems. In 1982, ABC became the first exporter to own and develop its own ventilation equipment for planes flying out of Miami International Airport. These three innovative systems reduced the overall stress on the animals and improved airflow. In sum, this reduced in-transport mortality rates drastically. $A B C$ used every resource at its disposal to ensure that, in addition to being the top exporter of cattle and swine from the United States, it is also the number one exporter with the lowest in-transport mortality. ABC knew that in order to achieve the first goal, it must also achieve the second. Experience, competencies, and knowledge were extracted from every possible source.

Borrowing for $A B C$ Exports is best exemplified by its development of production programs for a number of private firms as well as governments around the globe. In 1977, ABC was contracted to potentially supply Holstein dairy heifers to a farm in Hungary. It was initially involved in only supplying the cattle, but over the course of a year, it had helped with the development of a production program for the dairy herd. Equipped with the "borrowed" knowl- 
edge, it developed production programs with private industry in Spain for dairy production in 1979. ABC did not restrict itself to dairy production, but went on to develop programs in beef production (Government of the Philippines, 1983), swine production (Dominican Republic, 1983), and sheep production (Government of Rajasthan, Jaipur India, 1993). ABC Exports not only develops the production programs for its clients, but also supplies them with the animals (through live animals, embryos, or semen).

\section{Complementing Resources}

The third method of leveraging resources is by complementing one type of resource with another to create a higher order value. One approach to complementing resources is through the blending of resources: "...by blending different types of resources in ways which multiply the value of each, management transforms its resources while leveraging them. ${ }^{14}$ This blending may take place at a technical or functional level. The recent popularity of cross-functional teams in organizations attests to the belief in the efficacy of this concept.

The other approach to complementing resources is through the balancing of these resources. Hamel and Prahalad stress that any organization is like a three-legged stool. In order for the organization to be stable and strong, each one of the legs must be the same length: "...if any of the legs is much shorter than the others, the company will be unable to exploit the investments it has made in its areas of strength." ${ }^{5}$ An organization will not be able to fully leverage its available resources if it does not have balance and control over its various dimensions.

$A B C$ Exports Mr. Smith believes in the idea of blending resources to increase the value of each one and the whole. He works closely with his staff, and effectively they jointly have control of the operation. For $A B C$, its strength is in its personnel. The firm has collected a set of people with specific technical or regional expertise. The combination of these individuals means that clients are served by teams who not only provide them with the best animals available, but also with the most appropriate animals for their location in the world. This assures that the client is completely satisfied. ABC's teams always consist of a regional expert (Asia, Latin America, or Europe), a technical expert (dairy science, beef cattle, or swine specialist) and an international veterinary consultant.

$A B C$ is also quite skilled at balancing its resources. $A B C$ consists of technical, regional, and administrative expertise. It is able to leverage its meager resources (11 people) through cross-functional teams. These teams work to the goal of complete client satisfaction through top-notch inspections and health screening, expert selection based on regional constraints, and seamless order processing and follow-up.

\section{Conserving Resources}

The fourth arena of resource leverage is the conserving of resources. Hamel and Prahalad suggest that by conserving resources wherever possible, organizations can create leverage. It is through recycling and shielding resources that conservation is achieved. Recycling is seen as a reusing of resources: "...the more often a given skill or competence is used, the greater the leverage...." ${ }^{\prime 16}$

The shielding of resources is also a way of achieving leverage through conservation. Shielding is the most similar to military tactics of all the other leverage techniques: $"$...the goal is to maximize enemy losses while minimizing the risk to one's own forces..."17 This means not engaging in a full frontal attack, to reconnoiter enemy territory, and to use the enemy's forces to your advantage. In essence, it is using the strategy of "entrepreneurial judo." ${ }^{18}$

$A B C$ Exports. Recycling is best exemplified for $A B C$ Exports through the saying "sticking with your knitting." Once it had developed the air ventilation, watering, and metal pen systems for air transport of swine in 1982, ABC stuck with what it knew and used the same technological innovations for the transportation of beef and dairy cattle and sheep. It simply adapted the systems to the different animals' requirements. The same stick-with-it-ness is also shown in the dairy production program developed for the Hungarian government. This program was used as a template for future production programs for various governments around the world.

$A B C$ has done an excellent job.of shielding its resources by concentrating on the export of cattle and swine. This does not open it up to attack from other animal exporters. If it were to greatly expand its product line, it would be exposed to more risky ventures. In 1993, ABC Exports ventured into the exporting of sheep to India. There are ongoing discussions at $A B C$ to expand into sheep exports with the success of the India contract. Mr. Smith is loath to move beyond cattle and swine, as they are the two most profitable species for animal exporters. The specialization in cattle and swine protects the firm's resources by not spreading them too thin. Cattle and swine exports represent the two most profitable lines for animal exporters with sheep coming a very distant third. ABC conserves its resources by only concentrating on the most profitable exports.

\section{Recovering Resources}

Hamel and Prahalad's final method of leverage resources is found through the recovery of these resources. The most leverage is achieved if the resources are recovered from the marketplace in the shortest possible time: "...the more rapid the recovery process, the higher the resource multiplier...."19 This means that organizations, which can per- 
form functions faster than their competitors (expedite), will have a leverage advantage. Organizations that have a faster turnaround time with their products and technology are also able to use recovery as a means of leveraging resources. These organizations are able to recover their resources, reorganize them, and then put them quickly back into the melee. This allows them to preempt their competition.

$A B C$ Exports. The opening of ABC-Europe in 1992 was initiated to get a jump on the competition. ABCEurope allows the firm to reduce client response time. It is able to expedite orders and greatly cut down on client service time. $A B C$ 's European office also enabled $A B C$ to move its regional expertise closer to its clients. This enabled the company to gain the upper hand with its competition. In keeping with its preemptive strategy, $A B C$ is looking to open ABC-Asia in the near future.

\section{Maneuvering Resources}

The area of maneuvering resources is not restricted to military use and is seen in many organizations. The maneuvering of resources to increase productivity is directly related to allocation, but it is more than simply putting resources in their place. Maneuvering requires both flexibility and coordination.

To use the tool of flexibility, managers must first determine the range of allocation possibilities for each resource. This allows the manager to decide which resources to use in certain circumstances. For example, in many smaller firms, the owner/operator also functions in many areas (e.g., marketing, production, distribution, etc.). This one resource can be (and often is) allocated in a variety of areas. As managers are able to increase the flexibility of resources, they find they can accomplish much with very few resources.

Maneuvering also requires coordination. For effective resource leveraging to take place, the resources must be in balance with one another, moving in concert with each part, and their movements must be perfectly timed. For resources to be effectively maneuvered, they must have flexibility and coordination working together in tandem.

$A B C$ Exports. $A B C$ has increased its flexibility through cross-functional teams, innovations in technology, and a regional office. ABC's cross-functional teams give it a complementary resource base. Teams of technical, regional, and administrative experts work together to meet client needs. They are able to quickly pinpoint client issues and solve problems. The teams are also able to draw on one another's expertise as well as creativity, thus giving the client better service. Whether the problem is administrative or technical, the team is there to come up with solutions for the client. This flexibility has enabled ABC Exports to attain its goal of being the number one exporter of cattle and swine from the United States.

On the innovation front, ABC's developments have moved the company into the premier position in the world. Its development of ventilation, hydration, and penning systems has given the firm very solid ties to clients. The ventilation, hydration, and penning systems were first developed for cattle, but had the built-in flexibility to be adapted for swine and latter for sheep. The systems were developed for 747 aircraft, but again have the flexibility for adjustment for other plane sizes. While the equipment has not been used for rail or truck transport (as these mode of transport are more short-haul), there are plans for a railcar hydration and penning system for the 21st century.

ABC-Europe is probably one of the best examples of resource flexibility at work. This office is now able to serve clients better in Europe, the former Soviet Union, the Middle East, and Africa. Their response time to clients has been dramatically reduced since $A B C$-Europe opened in 1992. This center of regional expertise has moved $A B C$ into the number one spot for dairy cattle exports.

$A B C$ has achieved coordination through satellite tracking of shipments; computer databases on clients, suppliers, and competitors; and on-line client assistance. Satellite tracking systems allow ABC Export's clients to obtain up-to-the-minute information about their shipments. Since $A B C$ deals either in live animals or frozen embryos/semen, it is vital that the shipments be made in a timely manner. Satellite tracking enables the company to coordinate the various transportation systems it uses to ensure on-time delivery.

ABC's databases on clients, supplièrs and competitors helps the firm keep up on its clients, the latest innovation, or a competitor's strategic move. All ABC teams keep current files on clients, allowing them to service clients more efficiently. Instead of carrying a variety of files, the teams just access the client database of all information. Current and past sources of supplies are also on the database. Thus, if a client prefers a certain breeder, $A B C$ will have current information on that supplier. Finally, the firm's competitive database lets it assess any strategic maneuvering from their competitors. These computer databases help coordinate the strategic thrust of $A B C$.

$A B C$ 's on-line client assistance goes further to help coordinate actions to satisfy client needs. Clients can simply access an on-line system that will help them with simple technical problems. It also allows them to leave messages for their client team, which are then relayed directly to the team. This on-line system has gone a long way to improving already good client relations.

In sum, the most interesting aspect of analyzing $A B C$ Exports in the context of the six arenas of manuevering is that it used all six in order to be globally competitive. Although later in this article six firms will be discussed that 
used one of the arenas to compete internationally, $A B C$ has effectively used all six. $A B C$ needed to utilize all available competitive strategies to be successful in a very fragmented genetic sourcing industry. In this industry, genetic materials, such as semen, eggs, or live animals are frequently sold by the breeder themselves to other breeders. This has created a very regionalized industry. $A B C$ Exports is one of a handful of global sourcing companies. Its customers can access a whole host of genetic materials from around the world. Therefore, it was necessary for $A B C$ to not only use manuevering, but also conserving, accumulating, recovery, complementing, and concentrating to become number one in the industry.

\section{Research and Managerial Implications}

This article is designed to offer insights to SME managers drawn from the case of $A B C$ Exports. This section details a set of insights from each of the "arenas."

\section{Concentrating Arena}

Focusing on key strategic goals is often the secret of success for many SMEs in the global marketplace. They do not attempt to "be all things." They converge on a few goals and achieve them. Convergence is the first tool that can be used in the concentrating arena. The second tool is focus. These two tools give SMEs direction for competition. The strength of many SMEs is built on their understanding and commitment to a goal for the firm and not spreading themselves too thin. In fact, it is often when these smaller firms attempt to proliferate their goals that they run into difficulty.

Hike Metal of Canada has used concentration to its advantage to become the world leader in the manufacturing of search-and-rescue boats for naval operations. ${ }^{20}$ This small firm manufactures the "self-righting" search-and-rescue boats preferred by coast guard operations around the world. When capsized in heavy seas, these boats will "right" themselves in minutes, thereby increasing not only the safety of these types of operations but also allowing search-and-rescue missions to continue in rougher conditions.

Hike Metal began operations by designing and manufacturing the Maid of the Mist boats used at Niagara Falls to ferry tourists up the Niagara River to the foot of Niagara Falls. These boats have extremely powerful engines and are designed to resist capsizing. Hike was able to take its technology for the Maid of the Mist boats and translate it for search-and-rescue boats. The firm converged on one single goal: "to become the small boat of choice for North American Coast Guard Operations." This focus allowed Hike to concentrate resources to achieving that goal. Not only is Hike the choice of Canadian and American searchand-rescue teams, but European teams as well.

\section{Accumulating Arena}

In the second arena, the tools are extraction and borrowing. For managers of SMEs these tools translate into the squeezing of every ounce of value from each resource. It is stretching that little bit extra out of capital and human resources. These are common activities for SMEs, where resources are at a premium and no amount of waste is acceptable. Another day-to-day activity for many SME managers is the borrowing of resources from "friends and enemies." This tool is much more than loaning a piece of equipment. It most often seen in gaining access to a new set of skills and then learning and internalizing them into the firm. In a way it is the least costly method of accumulating resources such as skills and knowledge. It does not actually require the physical acquisition of the resource but the skills/know-how associated with those resources.

An excellent example of a medium-size firm that competed in the accumulation arena to compete globally is Psion Computers. This 500 -employee, UK-based company is Europe's leading producer of handheld computers. ${ }^{21}$ Psion began not as a manufacturer, but as a developer of computer game software. Over its 20-year history, Psion has accumulated resources to move it from concentrating exclusively on the development and distribution of gaming software to manufacturing and marketing of handheld computers. This transformation was assisted with the tools of extraction and borrowing. The educational background of Psion's employees runs the gamut from medieval history to astrophysics, but the commonality is their originality, flair, and willingness to accept both an unconventional job and company. With this eclectic group, Psion was able to pull from them a variety of problem-solving and decision-making skills. It was then positioned to research, analyze, and report on the market, the hardware and software for computers. It saw an opportunity to move into handheld database management. The problem was that Psion was a developer of software, not a manufacturer of hardware. By borrowing resources from a variety of competitors, suppliers, and customers, Psion launched the Organizer in 1984. It borrowed skills and resources from manufacturers and distributors of software, and then internalized them into its own organization. Today, Psion remains on top of the handheld computer industry worldwide.

\section{Complementing Arena}

In order to compete in the complementing arena, SMEs must blend their resources through an intimate understanding of how each of the resources fits together. Managers must also balance their resources so that they build on the strengths of each resource, thereby "springboarding" all of the firm's resources. With the increasing popularity of crossfunctional work teams, many SMEs are using complementing as a way of competing internationally. SMEs that put 
together teams of individuals who have different but complementary skills, are indeed able to do more with less. Effective teams are those that do not have extremely dominant members. Rather, they are made up of a set of balanced participants whose complementary skills allow the team to creatively solve problems. SMEs that compete internationally often do not have a complete set of skills inhouse for global management. Many will bring in new talent on a permanent basis. Increasingly, however, managers of SMEs are balancing their teams with temporary new members. These managers recognize the need for new skills that the firm needs to blend with existing skills, and they contract out for these new resources. This leads to a balanced set of resources. This can be seen with SMEs who decide to enter the international market through exporting. Many firms will not have the requisite skill set to export, so they contract to an export consultant to assist them in acquiring these skills. Once the firm has become efficient at exporting and has internalized the skills, it then reverts to its original complement of employees but with a greater skill base of resources.

Oticon Hearing Care is a good example of a firm that uses the complementing arena to compete effectively on a global scale. This Danish company has established itself as a world leader in hearing care. ${ }^{22}$ The firm's open-concept office and "multitask job profiles" have moved it from a product-based to a solution-based firm. Oticon uses the tools of the complementing arena very effectively. It blends its human resources through a project-based management structure rather than one that is functionally structured. Employees work in open-concept offices with mobile desks, cellular phones, and laptop computers. This crossfunctional team-based organization combines skills sets to create solutions for customers' hearing problems. It believes that solutions come from anyone, not just the "experts." The teams consist of a set of experts, each with specific knowledge in marketing, engineering, production, etc. This delicate balancing of resources allows for more creative and innovative ideas and a shared understanding of each other's problems. This, in turn, sets up what Oticon terms "multiple solution modes," where the problems are tackled from many angles and the best solution is created.

\section{Conserving Arena}

The tools used in the conserving arena are recycling and shielding. Most often SMEs are well acquainted with recycling and shielding, as they operate with fairly few resources. Recycling resources and protecting them from the competition is the norm of day-to-day operations for SMEs. SMEs often compete in this arena as it is a very natural place for them to be. Many entrepreneurs learn how to use the same set of skills or resources in many different forums. For instance, many firms create a product or ser- vice and then look for alternative uses for that product or service. Once alternative uses are found, the firm then expands either geographically or through an augmentation of the product line. This recycling is the most common form of entry into the global market. SMEs discover that their product or service has a potential market outside of their domestic domain. They then export that product to the new, market, and another international firm is born.

Tropical Import/Export is a small firm that uses conservation as its method of leveraging resources to compete globally. This firm, located in the southwestern United States, imports premium cigars from Indonesia and the Philippines ${ }^{23}$ It competes in the conserving arena through exclusive contracts with cigar manufacturers, which allows the firm to shield its very important resources from potential competitors. Tropical is also currently creating its own brand of premium cigars which will enable it to recycle its skills of importing and contracting distributors for these new cigars.

\section{Recovering Arena}

To compete in the recovering arena, SMEs must be first to the market in satisfying customer needs. They must continually preempt their competition and perform functions such as order processing, delivery, and customer service faster than anyone else in the marketplace. For firms in the recovery arena, this is their source of leverage. In fact, this arena is best suited to small- and medium-sized firms, which tend to be closer to their customers and thereby are able to more quickly react to changing.customer needs and wants.

A good example of a small firm that has used the recovery arena to compete globally is Angler's Expressions of the United States. This five-person company sells gift items with a fly-fishing motif. ${ }^{24}$ After initial success in its domestic market, Angler's Expressions began to look internationally for an expanded market. It identified an emerging niche market in Asia that was showing great interest in fly-fishing. Jumping on this research, the firm was able to secure the first orders for hats, mugs, T-shirts, and other giftware for a Japanese firm. The ability to preempt its competition and the rapidity with which it performed functions has made Angler's Expressions one of the most successful giftware exporters in the western United States. It currently exports to several Asian nations as well as Europe.

\section{Maneuvering Arena}

Maneuvering requires a tandem effort of flexibility and coordination. For many SMEs, the reality of extremely scarce resources requires imaginative strategies in resource allocation. Maneuvering resources allows firms to 
cross-employ resources, thereby increasing their flexibility. The coordination of these cross-employed resources is of central importance. It is vital to maintain an overview of where resources are deployed and in what capacity. Many SME managers find themselves and their staff wearing many hats. In these situations, they have been able to create maximum flexibility and, in those successful SMEs, they have been able to creatively coordinate the allocation of scarce resources.

An example of an international SME that has worked in the maneuvering arena is the Kimble Group of the United Kingdom. It is the fourth largest hairdressing group in the world. ${ }^{25}$ Kimble began as a single hairdressing shop in England and has grown to include shops around the world. The founder was able to accomplish this international growth through franchising, a viable option for SME managers looking to compete in the global marketplace. Maneuvering requires flexibility and coordination, as the franchisor manages the international strategy for the firm. For the Kimble Group, its scarce resources of capital and personnel were used flexibly through franchise agreements where the franchisees used their own capital and personnel to own and operate Kimble Group hairdressing shops. The Kimble Group coordinates its own global strategy using franchising arrangements to augment its limited resources.

\section{Conclusions}

This article has presented the findings of one case study. The findings here support McLarney and Chung's study of the Battle of Midway. These two different case studies, pertaining to scenarios at different time periods, both support the idea of maneuvering of resources as a viable means of resource leveraging. Other researchers may want to study other cases to arrive at other findings. Would investigations into other similarly turbulent decision-making environments yield similar findings? If so, greater confidence in the results presented here would be achieved. Alternatively, it may also be beneficial to test the model under different situations and see how to better refine the model itself. Along these lines, researchers may examine other contemporary scenarios and identify whether some of the model parameters may have changed over time. If anything is generalizable, it would be insights that each reader experiences. Confidence in the validity of the findings will increase if other studies are able to replicate the ethos of the present analysis. To the extent that quantitative analysis is possible, confirmatory findings will add further credence to the arguments raised here.

For practicing managers, this article points out some of the dangers that may often be overlooked. For example, the need to establish a thorough search for and dissemination of competitive and market intelligence is clearly demonstrated. In addition, this article has shown that resource superiority does not guarantee victory. Using the idea of maneuvering of resources, managers can attempt to leverage their resources so that they can do more with less. The $A B C$ case study, which supports the earlier findings from the Battle of Midway, demonstrates how resource maneuvering can be implemented and how it can help an enterprise compete in the global marketplace. The manager is also reminded of the negative consequences of being blinded by previous success. If nothing else, this is step one in preventing managers from being so blinded. As Hamel and Prahalad have commented, "long-term competitiveness depends on managers' willingness to challenge continually their managerial frames. ${ }^{\text {"26 }}$

\section{Endnotes}

1. G. Hamel and C. Prahalad, "Strategy as Stretch and Leverage," Harvard Business Review (March-April 1993), pp. 75-84.

2. C. McLarney and E. Chung, "Maneuvering at Midway: Leveraging Your Way Out of Annihilation," in J. Jaensson and G. Tesar, eds., Proceedings: The Annual Nordic Marketing Conference, Umea, Sweden, 1994, pp. 1-16.

3. Ibid.

4. M. Porter, Competitive Strategy. New York: Free Press, 1980.

5. Hamel and Prahalad, "Strategy as Stretch and Leverage," p. 77.

6. McLarney and Chung, "Maneuvering at Midway: Leveraging Your Way Out of Annihilation."

7. For a fuller account, see McLarney and Chung, "Maneuvering at Midway: Leveraging Your Way Out of Annihilation."

8. E. Penrose, The Theory of the Growth of the Firm. Oxford: Basil Blackwood, 1959.

9. Hamel and Prahalad, "Strategy as Stretch and Leverage," p. 78.

10. Ibid., p. 19

11. K. Andrews, The Concept of Corporate Strategy, 2nd. ed. Homewood, IL: Irwin, 1980.

12. Hamel and Prahalad, "Strategy as Stretch and Leverage," p. 80. 
13. Ibid.

14. Ibid., p. 81

15. Ibid.

16. Ibid., p. 82

17. Ibid., p. 83.

18. P. Drucker, "Entrepreneurial Strategies," California Management Review 27, no. 2 (1985), pp. 9-25.

19. Hamel and Prahalad, "Strategy as Stretch and Leverage," p. 83.

20. "Hike Wins Coast Guard Contract," Wheatley Journal, June 20, 1998, p. 1.

21. R. Lessem and S. Palsule, Managing in Four Worlds. Oxford, UK: Blackwell Publishers, 1997.

22. Ibid.

23. C. Hill, Global Business Today. Boston, MA: Irwin McGraw-Hill, 1999.

24. C. Freadhoff, "Small Businesses Take Part in Export Boom," Investor's Daily 34 (1991).

25. H. Deresky, International Management. Reading, MA: Addison-Wesley Longman, Inc., 1997.

26. Hamel and Prahalad, "Strategy as Stretch and Leverage," p. 76.

\section{HE'L}

Carolan McLarney is an assistant professor of strategic management and international business at Dalhousie University, Halifax, Nova Scotia, Canada. Prior to completing her Ph.D. at York University, she held management positions in various companies in the healthcare, transportation, and consulting sectors. 